\title{
Does Flipped Learning Promote Positive Emotions in Science Education? A Comparison between Traditional and Flipped Classroom Approaches
}

\author{
Malek Jdaitawi \\ Self-Development Department, Deanship of Preparatory Year \& Supporting Studies, P.O. Box \\ 1982, Dammam 31441, Saudi Arabia \\ mtmustafa@iau.edu.sa \\ DOI: 10.34190/JEL.18.6.004
}

Abstract: Flipped learning has become a popular approach for supporting higher education, but less is known about its link with the learners' emotions, which are known to play an important role in science education. The main purpose of this study is to analyse the effects of the flipped learning approach on students' learning emotions. This research utilised a quasiexperimental design with two data collection time points (pre- and post-study). The sample involved 65 students from the science track in one Saudi university. The participants were distributed into two groups, taught by the traditional and the flipped learning methods respectively. Data collection took place over a period of 4 study weeks. The results show that the flipped mode group had obtained higher learning emotions mean score compared to its traditional counterpart, and they showed improvement in learning emotions mean score over the period of the study. The findings indicate that further study is needed both to validate the current study in a different context, and also to determine how the flipped learning environment can better support students' interactions and their emotions.

Keywords: Emotions and learning, flipped learning, university, science education

\section{Introduction}

Science education primarily aims to develop a specific degree of scientific understanding among individuals to support formal education in schools (Wang and Schmidt, 2001). Higher education reforms have underlined the increasing concerns of the science educational model's capability of arming university students with the required skills to develop their future careers. In fact, several attempts have been made in the science field to tackle the issues that students face including disengagement and negative attitudes towards science education (Howard, 2017), with the approach to which such education is delivered falling short of meeting time demands (Cagande and Jugar, 2018). In this regard, Thornburg (2009) presented five main challenges faced by science students that require addressing by educators to meet societal expectations; 1 ) lack of qualified teachers, 2) learning science not only as a subject but a dynamic human activity, 3) lack of hands-on sciences learning, 4) learning science as an inquiry and actual process and 5) relating science to other subjects. Other studies such as Jeong, et al., (2019) revealed that traditional teaching methods in science are not effective in instructing students and this increasing concern on the science education quality necessitates a shift from the traditional didactic teaching approach (Weiman, 2008a) for the preparation of students' future career development. Presently, there are different learning methods that have been introduced to keep abreast with the dynamic ongoing societal changes and scientific and technological developments (Sojayapan and Khlaisang, 2018). Undoubtedly, science education is among the top disciplines that could be easily learned through the use of technologies (Cagande and Jugar, 2018). However, Mc Laughlin, et al. (2016) stated that one of the more popular learning methods resulting from the developments in technology and pedagogy is flipped learning. Such learning is based on the principle of active learning and in higher education, literature has, time and again, highlighted the value of the flipped classroom method and its positive effect on the learning outcomes of students (e.g., Kwon and Woo, 2018; Jdaitawi, 2019). In fact, Jdaitawi (2019) claimed that flipped classroom is one approach that could minimize classroom time spent on lectures that are teacher-centered, while at the same time relaying sufficient learning content. Flipped classroom, also known as inverted classroom, is an instructional model, whereby the lecture material that is delivered in the classroom to the students is delivered online instead, before class begins, in order for the students to review, practice and apply knowledge (Sojayapan and Khlaisang, 2018). Other studies like Chen, et al. (2014) and Lai and Hwang (2016) revealed that flipped classroom is an alternative to in-class lectures, equipped with collaborative practical activities and it requires students to revise the course material on their own. Similarly, flipped classroom was described by Burke and Fedorek (2017) and Bergmann and Sams (2012) as an approach whereby the instructor would enable students' display of more in-depth understanding of the material, compared to the traditional approach. It is noteworthy that learning strategies play a key role in 
the outcomes of learning (Yousefzadeh and Salimi, 2015), while relating with the learning emotions of students (Abar and Loken, 2010). Additionally, increasing evidence revealed that non-traditional approaches are more capable of promoting students' positive attitudes and emotions (Roach, 2014). In relation to this, active learning has been often linked with higher degrees of motivation, confidence and critical thinking skills of students, as well as their learning abilities, particularly in science (Machemer and Crawford, 2007; Jeong, et al., 2019). In the same vein, researchers such as (Borrachero, et al., 2014; Fared, Jdaitawi and Sheta, 2018) have connected the learning and teaching process and academic success with the cognitive and affective dimensions. Initially, the constructive theory highlighted the important role of emotional dimensions in teaching and learning environments (Ross, 2012). Literature also indicated that emotions play a crucial role in the learning and teaching process, particularly in science (Pintrich, Marx and Boyle, 1993; Mellado, et al., 2014). Therefore, there is a need to consider emotions in the teaching and learning strategies of a certain course, in a way that controls and regulates affective dimensions which promote positive emotions (e.g., enjoyment and learning pride) (Vazquez and Manassero, 2007; Aydogan, Bozkurt and Coskun, 2015; Brigido, et al. (2010) and Jeong, et al. (2019). Bradford (2005), states that people produced different emotional responses in their daily interaction.

Against this background, flipped learning is able to promote students' positive learning emotions, which could increase their active learning, enjoyment, and accomplishment of their goals. Some other studies highlighted the under-reporting and under-examination of flipped classroom in science studies (e.g., Jeong, Canada and David, 2018; Love, et al., 2013) and the majority of studies in the topic of the flipped classroom examined the performance of students depending on the traditional approach (Patterson, et a., 2015); on different subjects at different study levels (Blair, Maharaj and Primus, 2018), but only a few focused on university students' learning emotions. Hence, in the present study, the effects of flipped learning among first-year university students are investigated by answering the following research questions;

1. Does the use of the flipped learning approach with science students promote positive learning emotions?

2. Do science students, who are taught by the flipped learning approach, obtain better mean scores of positive learning emotions compared to students, who are taught using the traditional approach?

\section{Literature Review}

\subsection{Flipped Learning}

A flipped learning approach was described by Sojayapan and Khlaisang (2018) as an instructional strategy that advocates a reversed version of the traditional learning environment wherein, instructional content is delivered online outside of the classroom. It is a learning strategy that brings about learning with the help of technology, particularly with the help of online video media that assist in listening lecturing time and maximizing students' activity time, which can be used in learning cooperatively and practically (De-Lozier and Rhodes, 2017). Moreover, a flipped classroom model is a combination of traditional and online education systems, where inand out-of-class time is used to facilitate effective learning opportunities and perspectives (Munir, et al., 2018). Furthermore, this approach has been evidenced to bring about self-regulation, engagement, sense of responsibility for work, teamwork and participation in classroom activities among students (Yilmaz, 2017; Panich, 2013).

\subsection{Learning-Related Emotions}

Academic emotions, based on the control-value theory of academic emotions by Pekrun et al. (2002), stem from value appraisals that the student relates to learning and outcomes of learning well as those relating to learning tasks control. According to Perkun et al. (2002), academic emotions refer to a set of emotions that the students go through when taking part in academic activities (e.g., studying, learning and following instructions). In the learning process, emotional detection is a must (D'Mello, Jackson and Craig, 2008), with positive emotions relating to positive outcomes, high achievement level, high motivation level, informed decision making and skillful problem solving skills (Trigwell, Ellis and Han, 2012; Hannula, 2012; Lewis, et al., 2011; Linnenbrink, et al., 2011). In contrast, negative emotions negatively affect learning (Goetz, et al., 2014).In relation to the above, studies in literature highlighted different emotions that learners experience (Kort, Reilly and Picard, 2001) and these included boredom, confusion, anxiety, appreciation, engagement, motivation, happiness, pride and shame (e.g., Altrabsheh, Cocea and Fallahkhair, 2015). Also, D'Mello, Jackson and Craig, (2008) revealed that positive emotions may lead to increased learning interest, increased engagement in the class and increased motivation among students; and happy students are more motivated to achieve their learning targets. Along a similar line of study, Velayutham and Aldridge (2013) stated that a positive learning environment is a top element of 
students' learning motivation, while Pekrun, et al. (2002) revealed that positive emotions are considered to be the core of achieving learning and education goals. Furthermore, flipped learning mode assists in the enhancement of students' performance, reinforces their interest in the course, and promotes their self-efficacy through active learning strategies that can be included as a result of maximized time in the classrooms.

\subsection{Role of Flipped Learning in Promoting Positive Emotions Related to Learning}

Towards the end of the $20^{\text {th }}$ century, colleges and universities began adopting inverted classroom approach to improve the learning outcomes of students. However, it was not until recently that inverted instruction methods, like flipped learning, have begun to garner attention in higher education, particularly in science courses (Jeong, et al., 2019). It is considered to provide a more suitable learning environment that achieves a significant level of learning in light of affective domains and performance of students (Blair, Maharaj and Primus, 2016; Roach, 2014). The flipped mode assumes that students' participation and engagement in their classroom activities as well as their learning may be enhanced (Jeong, Canada and David, 2018). Added to this, flipped classrooms are able to provide engagement, and in turn, satisfaction and retention of students (Burke and Fedorek, 2017). Generally speaking, the instructional method adopted affects the emotional learning of students (Joeng, et al., 2019). Moreover, the adopted instruction method and its delivery of content may directly impact students' academic emotional experiences (Goetz, et al., 2013). In the case of science courses, Pintrich, Marx and Boyle (1993) found that positive emotions do have a key role in fostering learning. Stated clearly, positive emotional conditions improve students' learning and development of science, whereas negative emotional conditions hinder them (Aydogan, Bozkurt and Coskun, 2015). Hence, a suitable instruction method should be adopted to enhance positive emotions in order that the learning process of students is positively affected (Jeong, et al., 2019). In their study, Jeong, Gonzalez-Gomez and Canada, (2016) demonstrated that university students have positive perception and positive emotions to a flipped classroom setting. The study also suggested confirming its result by conducting another study focusing on the learning-teaching environment. Hao (2016) also surveyed 84 undergraduate students and the statistical result showed that students' felt positive toward flipped learning by agreeing that flipped classroom met their learning needs. Wilson (2013) also found that undergraduate students' attitudes have been statistically positively changed after having a flipped classroom learning experience. However, he suggested examining the effect of flipped classroom on students from different milieus and various classrooms. Although some studies (Jeong, et al., 2016) claim that students taught in flipped classroom may score higher positive emotions than students exposed to traditional methods of teaching, other studies indicate that students' response and attitude towards flipped classroom are not comprehensively positive (Wilson, 2013; Missildine, et al., 2013). Thus, the current study seeks to better understand the flipped classroom method, by investigating the science track students' emotions towards learning of the flipped classroom.

\section{Methods}

\subsection{Design}

The research follows a quasi-experimental design with two groups of first year university students. The study involved a quasi-experimental design due to the fact that the design allows the students to be randomly selected from the population and does not require the random assignment of individual cases to the comparison groups (Muthomi and Mbugua, 2014). In addition, the students were assigned by the researcher since they worked with existing streams and students (Nachmias and Nachmias, 2004). The study focused on science track classes with the syllabus including topics and content relating to the subject. As the study's independent variable, is a learning mode with two levels: one group that interacted with a flipped learning mode and another group interacted with the traditional learning mode. The study dependent variable was the learning related emotions, which has two dimensions: 1) emotions related to study and 2) emotions related to test. Flipped and traditional groups were exposed to 4 weeks of learning, given a M1 prior to the study and M2 after completing the study. Both measures were performed through the Statistical Package for the Social Science (SPSS) software.

\subsection{Participants}

The participants involved in this study were in classes studying a compulsory general course from the Science track. The study subjects comprised two groups of 65 science students of Imam Abdulrahman Bin Faisal University, located in Dammam city in Saudi Arabia. The sample was selected through purposive sampling from two groups of students, as there was a sufficient number of students available for the experiment, along with the suitability of the school's technological equipment in the form of internet and infrastructure. They were randomly divided into flipped (33 students) and traditional classrooms (32 students). 


\subsection{Procedures}

This study was conducted in compliance with the ethical research standards of Imam Abdulrahman Bin Faisal University, as permission was sought from the university's college. Accordingly, prior to participation, the researcher obtained the voluntary participants' permission and they were informed about the goals of the research and its duration. Students were assured that all of their answers would remain confidential and used for this research purpose only. Two groups from the Science track were randomly chosen to participate in this study. Flipped and control groups were exposed to 4 weeks of flipped classroom and traditional learning mode, given a M1 prior to the study and M2 after completing the four weeks of the study. Before the start of the study, students were invited to participate in the study by explaining the study's benefits in terms of desire learning emotions, situation that resulted in student's acceptance. At the of the first meeting, the students completed the learning related emotions M1 data collection. Once the instructor received the M1 data, the instructor started giving students roles in every single session in order to save the session time. The units of instruction used in this study were limited to four topics and sessions ( 2 hours every session) of the self-communication course syllabus. The communication course topics were taught to students and were discussed and evaluated as well as students work together to correct each other. Furthermore, students were given time to present a practical activity to prove that they mastered the skills. These tasks were worked on out-of class schedules and available to students on the Blackboard platform. Students in the traditional group were taught by lecturing method. After completion the tasks, students were given the learning related emotions scale M2 and feedback was provided.

\subsection{Data Collection}

To determine students Learning Related Emotions (LRE), a LRE scale was employed twice, at the beginning (M1) of the study and another one at the end (LRE scale M2). The instrument used for collecting data was adopted from Pekrun, Goetz and Perry's (2005). The scale allows identifying emotions experienced by students in their class and during tests through 15 items, distributed in two components, namely: class emotions and tests emotions. Class emotions refers to emotions experienced during classroom instruction such as enjoyment and anger (I enjoy being in class; I am confident when I go to class). Tests emotions refers to emotions occurs after taking tests and exams (I am proud of how well I mastered the exam; I feel panicky when writing an exam).

Learning related emotions scale is a self-report questionnaire with a Likert scales ranged from 1 (strongly disagree to 5 strongly agree. The instrument's content validity was confirmed by five experts. Cronbach's alpha value was also obtained to confirm reliability, which was at 0.91 .

\section{Data Analysis}

This study used SPSS to analyze data, specifically using descriptive statistics, t-test and ANOVA test by conducting a comparison of difference in means. The sensitivity of statistical analysis to non-normality necessitated conducting the skewness and kurtosis normality tests (Tabachnick and Fidell, 2001). Skewness and kurtosis acceptable values lie between $\pm 3.00,7.00$ respectively. The skewness and kurtosis values of the original data set with the original respondents' number (65) are presented in Table 1. It is evident from the tables that the kurtosis and skewness values are acceptable.

Table 1: Results of Normality Measurments

\begin{tabular}{|l|l|l|}
\hline Main Variables & Skewness & Kurtosis \\
\hline Learning Related Emotion M1 & -.591 & -.230 \\
Learning Related Emotion M2 & -.788 & .278 \\
\hline
\end{tabular}

On the basis of the table, data based on the measurements indicated normality as skewness and kurtosis values lie within acceptable range $(+1.96,-1.96)$. In Table 2 , values of mean and standard deviation of the M1 and M2 scores are displayed. From the table, the study participants' mean scores revealed an increasing trend over the period of study in terms of learning related emotions. More specifically, M1 prior to the experiment the learning related emotions of the whole sample obtained a mean score of $(M=51.27, S D=12.37)$, and $M 2$ following the experiment, learning related emotions of the same sample obtained a mean score of $(M=60.33, S D=6.56)$. For the flipped mode group, the $M 1$ of the learning related emotions scores obtained were $(M=50.80, S D=12.39)$, which were lower compared to its traditional counterpart $(M=51.70, S D=12.51)$. But for the $M 2$ scores, the flipped mode group obtained higher mean scores $(M=64.35, S D=4.91)$ compared to its traditional counterpart $(M=56.67, S D=5.70)$, and they showed improvement in learning emotions mean score over the period of study. 
Table 2: Summary Statistics for Learning Related Emotions Scores $(\mathrm{N}=65)$

\begin{tabular}{|l|l|l|l|l|}
\hline Variable & & Experimental Group & Control Group & Total Sample \\
\hline \multirow{3}{*}{ Learning Related } & M1 Mean & 50.80 & 51.70 & 51.27 \\
\cline { 2 - 5 } & SD & 12.39 & 12.51 & 12.37 \\
\cline { 2 - 5 } & M2 Mean & 64.35 & 56.67 & 60.33 \\
\cline { 2 - 5 } & SD & 4.91 & 5.70 & 6.56 \\
\hline
\end{tabular}

The initial analysis was conducted to determine the changes over the study period in terms of learning related emotions, according to 0.05 significance levels. In addition, the paired sample test was conducted to provide the significant difference between the $\mathrm{M} 1$ and $\mathrm{M} 2$ based on the results the mean scores of learning related emotions of $M 1 \quad(M=51.27, S D=12.37)$ increased to $(M=60.33, S D=6.56)$ in $M 2$. Based on the paired sample test, the mean difference obtained between $\mathrm{M} 1$ and $\mathrm{M} 2$, is $(\mathrm{M}=-9.061$, $\mathrm{t}=-5.537$, sig=.000<0.05) and thus, overall mean scores among science students' learning related emotions improved during the study as shown in Table 3. .

Table 3: Results of Paired Sample Test for Learning Related Emotions

\begin{tabular}{|l|l|l|l|l|}
\hline Variable & Mean Diff & t & df & Sig \\
\hline PretestM1 LREs-M2 LREs & -9.061 & -5.537 & 64 & .000 \\
\hline
\end{tabular}

In the second analysis, the differences between flipped mode and traditional mode groups were ascertained in terms of their learning related emotions $M 2$ based on the significance level of 0.05 . Based on the independent sample t-test results (refer to Table 4), significant difference was found between the two groups in terms of learning related emotions M2 4, sig=.000<0.05). Also, ANOVA results (refer to Table 5) supported the significant differences between the groups in terms of learning related emotions $M 2$ scores. Additional investigations into the groups indicated mean and standard deviation values of the flipped learning group scores surpassed those of the traditional learning group.

Table 4: Results of Independent Sample T-test for Learning Related Emotions

\begin{tabular}{|l|l|l|l|l|l|}
\hline Variable & & F & Sig & T & Sig.2 tailed \\
\hline \multirow{2}{*}{ Learning Related Emotions } & Equal variance Assumed & 2.084 & .154 & 5.784 & .000 \\
\cline { 2 - 7 } & Equal Variance not assumed & & 5.824 & 62.80 & .000 \\
\hline
\end{tabular}

Table 5: Results of ANOVA for between-Subjects Effects of the Learning Related Emotions

\begin{tabular}{|l|l|l|l|l|}
\hline & Sum of Squares & Mean Square & F & Sig \\
\hline Between Group & 956.016 & 956.016 & 33.451 & .000 \\
\hline Within Group & 1800.538 & 28.580 & & \\
\hline Total & 2756.554 & & & \\
\hline$* P<.05$ &
\end{tabular}

\section{Discussion and Conclusion}

The results of this study revealed a significant difference between M1 and M2 scores of students based on their learning emotions. Furthermore, upon examining the M2 scores of the whole sample, it was evident that the learning emotions of the students towards learning were higher compared to the M1 scores. This may be attributed to the opportunities for interaction among students' themselves as well as interaction between students and their instructor in the flipped classroom mode, in addition to the preparation of course content at the students' convenience. Students were enabled to work individually and in groups and this may have assisted their familiarity and clarification of the subject, making it interesting to them and triggering their productivity and motivation via a competitive environment.

In recent times, students are inclined towards technology use in their day-to-day lives and their education as observed by instructors and hence, technological integration into flipped classroom can support their learning and promote their positive emotions towards it. Therefore, it can be stated that students' positive emotional level towards learning comes about through a flipped learning model application. In other words, the flipped learning mode allows students' participation in class activities as evidenced by prior studies. For instance, Hung (2015) indicated that flipped classroom mode promoted class engagements. Also, Jeong, et al. (2019) revealed that it assisted in achieving the students' learning goals and confidently accomplishing in-class activities and also promoting positive emotions. Mattis (2015) indicated that it promotes the students positive experience, while Tune, Sturke and Basile (2013) showed that it increases the motivation among students. Hence, the results 
obtained by the present study supports those reported by prior literature on flipped classroom mode's effective promotion of positive emotions towards the learning environment.

The result of this study was consistent with Baepler, Walker and Driessen (2014) study, which compared the effectiveness of the traditional classroom, with two active learning groups (flipped/blended) courses among 340 US university students, on students' satisfaction and their learning outcomes. The result showed statistically significant positive results for students who were taught in both active learning courses compared to their counterparts in the traditional group. Along the same lines, Strayer (2012)'s study compared two groups with different teaching methods. The first group consisted of 23 students having flipped classroom learning, and the second group consisted of 26 students having traditional classroom learning. The result showed statistically that students in the inverted classroom were more cooperative with both their preferred learning environment and their actual classroom experience than students in the traditional group. Smallhorn (2017) also compared students' engagement and their learning outcomes after replacing lectures with flipped classroom method activities. The results of the study showed students' engagement increased statistically with a positive attitude towards the learning method. Therefore, flipped classroom method may explain the increase in students' emotions mean scores from M1 to M2.

From the comparison results, it is evident that a significant difference exists in students' emotions towards learning between a flipped mode group and a traditional mode group. Specifically, students in the former group obtained higher scores in emotional engagement with learning compared to their traditional counterpart. In fact, the highest mean scores were obtained by the flipped learning mode group and thus, flipped learning mode is thus suitable to promote positive emotions of science students towards learning. Along a similar line of study, Aydogan, Bozkurt and Coskun (2015) reported that learning of science is fostered by positive emotional conditions, which leads to the commitment of students as active learners. Moreover, instruction methodology and the way the content is delivered may directly affect the academic emotional experience of the students (Goetz et al., 2013). In other words, flipped learning mode does enhance the positive emotions of students towards learning.

In conclusion, researchers have not yet agreed on the feasibility of the flipped classroom approach and the effectiveness of technology in the learning environment (Hao, 2016). Furthermore, previous studies have highlighted the important role of emotions in the learning process. Pintrich, Marx and Boyle (1993) pointed out that emotions play a key role in achieving significant learning in science courses. In other words, a positive emotional state fosters the learning of science and increases students' commitment in the active learning process; while negative emotions limit the learning ability (Vazquez and Manassero, 2007; Aydogan, Bozkurt and Coskun, 2015). Thus, in order to maximize the benefits of the flipped classroom, the study needs to know students' emotions towards flipped classroom learning experience. Therefore, this study contributed to the literature and confirmed that flipped learning mode is an effective approach to trigger and maintain positive emotions among science students. Students in the flipped learning group indicated higher learning emotions compared to those in the traditional learning group.

\section{Recommendations and Limitations}

This study experimented with two sample student groups numbering a total of 65 science course students. Because of the small sample size as well as the students were not randomly assigned to the two different learning modes, the generalizability of the findings with the general population should be done with caution. Other studies may reference the study in science education and in other courses and levels. Future works are recommended to increase the number of samples, and select them from various courses and levels for greater generalizability strength. This study was conducted in a short period of time owing to limitations in time, and as such, future studies can conduct a long-term study for accuracy and reliability of findings. Lastly, the study adopted a quantitative method, but future studies can adopt other data collection methods, like the mixed method to obtain the students' opinions and perceptions concerning the flipped classroom learning method.

\section{References}

Abar, B., and Loken, E., 2010. Self-regulated learning and self-directed study in a pre-college sample. Learning and Individual Differences, [e-journal] 20(1), pp.25-29. https://doi.org/10.1016/j.lindif.2009.09.002.

Altrabsheh, N, Cocca, M. and Fallahkhair, S. 2015. Predicting students emotions using machine learning techniques. $17^{\text {th }}$ International Conference on Artificial Intelligence in Education. Springer. [e-journal]. Doi:10.1007/978-3-319-19773956. 
Aydogan, H., Bozkurt, F. and Coskun, H., 2015. An assessment of brain electrical activities of students toward teacher's specific emotions. International Journal of Social, Behaviors, Educational, Economics, Business and Industrial Engineering, [e-journal] 9(6), pp. 2037-2040. doi.org/10.5281/zenodo.1107796.

Baepler, P., Walker, J. and Driessen, M., 2014. It's not about seat time: Blending, flipping, and efficiency in active learning classrooms. Computer \& Education, [e-journal] 78, pp. 227-236. 10.1016/j.compedu.2014.06.006.

Bergmann, J., and Sams, A., 2012. Flip your classroom: Reach every student in every class every day. Washington DC: International Society for Technology in Education.

Blair, E., Maharaj, C. and Primus, S., 2016. Performance and perception in the flipped classroom. Education and Information Technologies, [e-journal] 21(6), pp. 1465-1482. doi:10.1007/s10639-015-9393-5.

Borrachero, A., Brigido, M., Mellado, L., Costillo, E., Mellado, V. 2014. Emotions in prospective secondary teachers when teaching science content, distinguishing by gender. Research Science Technology, [e-journal] 32(2), pp. 182-215. doi:org.10.1080/02635143.2014.909800.

Bradford, M., 2005. Motivating students through project-based service learning. Technological Horizons in Education, [ejournal] 32(6), pp. 29-31. Retrieved from https://digitalcommons.unomaha.edu/slcestgen/92

Brígido, M., Borrachero, A., Bermejo, M. and Mellado, V., 2013. Prospective primary teachers' self-efficacy and emotions in science teaching. European Journal of Psychology of Education, [e-journal] 36(2), pp. 200-217. doi:10.1080/02619768.2012.686993.

Brígido, M., Bermejo, M., Conde, M. and Mellado, V., 2010. The emotions in teaching and learning Nature Sciences and Physics/Chemistry in pre-service primary teachers. US-China Educational Review, [e-journal] 7(12), pp. 25-32. Available through: ERIC website <http://eric.ed.gov/?id=ED514884> [Accessed 20 October 2018].

Burke, A. and Fedorek, B., 2017. Does flipping promote engagement? A comparison of traditional, online, and flipped class. Active Learning in Higher Education, [e-journal] 18(1), pp. 11-24. doi:10.1177/1469787417693487.

Cagande, J. and Jugar, R., 2018. The flipped classroom and college physics students motivation and understanding of kinematics graphs. Issues in Education Research, [e-journal] 28(2), pp. 288-307. Available through: ERIC website <http://eric.ed.gov/?id=EJ1175574> [Accessed 29 October 2018].

Chen, Y., Wang, Y., Kinshuk, S. and Chen, N., 2014. Is flip enough? Or should we use the flipped model instead? Computers and Education, [e-journal] 79, pp. 16-27. http://dx.doi.org/10.1016/j.compedu.2014.07.004.

D'Mello, S., Jackson, T., and Craig, S et al. 2008. Autotutor detects and responds to learners affective and cognitive states. Available at http://www.researchgate.net/publication/228673992 [Accessed 29 August 2018].

Fared, J., Jdaitawi, M., and Sheta, H. 2018. Fostering positive adjustment behavior: Social connectedness, achievement motivation and emotional-social learning among male and female university students. Active Learning in Higher Education, [e-journal] 19 (2), 145-158. doi.10.1177/1469787417731202.

Goetz, T., Frenzel, A., Hall, N., Nett, U., Pekrun, R. and Lipnevich, A., 2014. Types of Boredom: An Experience Sampling Approach. Motivation and Emotion, [e-journal] 38(3), pp. 401-419. doi:10.1007/s11031-013-9385-y.

Goetz, T., Frenzel, A, Pekrun, R. and Hall, N., 2005. Emotional intelligence in the context of learning and achievement. Cambridge, MA: Hogrefe \& Huber Publishers.

Goetz, T., Lüdtke, O., Nett, U., Keller, M., and Lipnevich, A., 2013. Characteristics of teaching and students' emotions in the classroom. Investigating differences across domains. Contemporary Educational Psychology, [e-journal] 38(4), pp. 383-394. http://doi.org/10.1016/j.cedpsych.2013.08.001.

Hannula, M., 2012. Exploring New Dimensions of Mathematics-Related Affect: Embodied and Social Theories. Research in Mathematics Education, [e-journal] 14(2), pp. 137-161. doi:10.1080/14794802.2012.694281.

Hao, Y., 2016. Exploring undergraduates' perspectives and flipped learning readiness in their flipped classrooms. Computer in Human Behavior. [e-journal] doi.org/10.1016/j.chb.2016.01.032.

Howard, S., 2017. Issues with science education and student disengagement. Science Teacher Education, 79. Available through: ResearchGate website <http://www.researchgate.net/ publication/320757346_Issues_with_science_education_and_student_disengagement_Article_in_Science_Teacher_ Education_ASE> [Accessed 26 November 2018].

Hung, H. (2015). Flipping the classroom for English language learners to foster active learning. Computer Assisted Language Learning, [e-journal] 28(1), pp. 81-96. doi:10.1080/09588221.2014.967701.

Jdaitawi, M. (2019). The effects of flipped classroom strategy on students learning outcomes. International Journal of Instruction, [e-journal] 12(3), pp. 665-680. doi:10.29333/iji.2019.12340a.

Jeong, J., Canada, F., and David, G., 2018. The study of flipped classroom for pre-service Science teachers. Education Science, [e-journal] 8(163). doi:10.3390/educsci8040163.

Jeong, J., Gonzalez-Gomez, D., Canada, F., 2016. Students perception and emotions toward learning in a flipped general Science classroom. Journal of Science Education and Technology, [e-journal] 25(5). doi.10.1007/s10956-016-9630-8.

Jeong, J., Gonzalez-Gomez, D., Canada, F., Pico, A. and Bravo, J., 2019. Effects of active learning methodologies on the student's emotions, self-efficacy beliefs and learning outcomes in a science distance learning course. Journal of Technology and Science Education, [e-journal] 9(2), pp. 217-227. doi:10.3926/jotse.530.

Kort, B., Reilly, R., and Picard, R., 2001. An affective model of interplay between emotions and learning: Reengineering educational pedagogy-building a learning companion. IEEE International Conference on Advance Learning Technologies. Madison, USA. 6-8 January. doi:10.1109/ICALT.2001.943850.

Kwon, J., and Woo, H., 2018. The impact of flipped learning on cooperative and competitive mindsets. Sustainability, [ejournal] 10(79), pp. 1-15. doi:10.3390/su10010079. 
Lai, C., and Hwang, G., 2016. A self-regulated flipped classroom approach to improving students' learning performance in a mathematics course. Computers \& Education, [e-journal] 100, pp. 126-140. http://doi.org/10.1016/j.compedu.2016.05.006.

Lewis, A., Huebner, E., Malone, P. and Valois, R., 2011. Life Satisfaction and Student Engagement in Adolescents. Journal of Youth and Adolescence, [e-journal] 40(3), pp. 249-262. doi:10.1007/s10964-010-9517-6.

Linnenbrink-Garcia, L., Rogat, T. and Koskey, K., 2011. Affect and Engagement during Small Group Instruction. Contemporary Educational Psychology, [e-journal] 36(1), pp. 13-24. doi:10.1016/j.cedpsych.2010.09.001.

Love, B., Hodge, A., Grandgenett, N. and Swift, A., 2013. Student learning and perceptions in a flipped linear algebra course. International Journal of Mathematical Education in Science and Technology, [e-journal] 45(3), pp. 317-324. doi:10.1080/0020739X.2013.822582

Machemer, P., and Crawford, P., 2007. Student perceptions of active learning in a large cross disciplinary classroom. Active Learning in Higher Education, [e-journal] 8(1), pp. 19-30. doi:10.1177/1469787407074008.

Mattis, K., 2015. Flipped classroom versus traditional textbook instruction: Assessing accuracy and mental effort at different levels of mathematical complexity. Technology, Knowledge and Learning, [e-journal] 20(2), pp. 231-248. doi:10.1007/s10758-014-9238-0

Mellado, V., Borrachero, A., Brígido, M., Melo, L., Dávila, M., Cañada, F. et al. 2014. Las emociones en la ense-anza de las ciencias (Emotions in the teaching of science). Enseñanza Ciencias, [e-journal] 32(3), pp. 11-36. Retrieved from http://www.eweb.unex.es/eweb/dcem/novedades.htm.

Missildine, K., Fountain, R., Summers, L., and Gosselin, K. 2013. Flipping the classroom to improve student performance and satisfaction. The Journal of Nursing Education, [e-journal] 52(10), pp. 597-599. doi:10.3928/01484834-2013091903

Munir, M., Baroutian, S., Young, B. and Carter, S., 2018. Flipped classroom with cooperative learning as a cornerstone. Education for Chemical Engineers, [e-journal] 23, pp. 25-33. doi.org/10.10160.ede-2018.05.001.

Muthomi, M. and Mbugua, Z. 2014. Effectiveness of differentiated instruction on secondary school students achievement in mathematics. International Journal of Applied Science and Technology, [e-journal] 4(1), pp. 116-122. Retrieved form http://www.ijastnet.com/journals/vol_4_No_1_January_2014/12.pdf.

Nachmias, C. and Nachmias, D. 2004. Research methods in social sciences, $5^{\text {th }} \mathrm{ed}$. London. Replika Press Ltd.

Panich, P., 2013. Flipped classroom. S R Printing Mass Product. Bangkok, Thailand.

Patterson, B., Geist, M., Larimore, D. and Rawiszer, H., 2015. Flipped versus traditional instruction and achievement in a baccalaureate nursing pharmacology course. Nursing Education Perspective, [e-journal] 36(2), pp. 114-115. doi: $10.5480 / 13-1292$.

Pekrun, R., Goetz, T. and Perry, R., 2005. Achievement emotions questionnaire user's manual. Munich: The University of Munich.

Pekrun, R., Goetz, T., Titz, W. and Perry, R., 2002. Academic Emotions in Students' Self-Regulated Learning and Achievement: A Program of Qualitative and Quantitative Research. Educational Psychologist, [e-journal] 37(2), pp. 91-105. doi:10.1207/S15326985ep3702_4.

Pintrich, P., Marx, R. and Boyle, R., 1993. Beyond cold conceptual change: The role of motivational beliefs and classroom contextual factors in the process of conceptual change. Review of Educational Research, [e-journal] 63(2), pp. 167199. doi:10.3102/00346543063002167.

Roach, T., 2014. Student perceptions toward flipped learning: New methods to increase interaction and active learning in economics. International Review of Economics Education, [e-journal] 17, (2014), pp. 74-84. doi.org/10.1016/j.iree.2014.08.003.

Smallhorn, M. 2017. The flipped classroom: A learning model to increase student engagement not academic achievement. Student Success, [e-journal] 8(2), pp. 43-53. doi: 10.5204/ssj.v8i2.381.

Sojayapan, C., and Khlaisang, J., 2018. The effect of a flipped classroom with online group investigation on students team learning ability. Kasetsart Journal of Social Science. doi:10.1016/j.kjss.2018.02.003.

Strayer, J. 2012. Who learning in an inverted classroom influences cooperation, innovation and task orientation? Learning Environment Research, [e-journal] 15(2012), pp. 171-193. doi 10.117/s10984-012-9108-4.

Tabachnick, B. and Fidell, L., 2001. Using multivariate statistics, (4ed). Needham Heights, MA: Allyn \& Bacon.

Thornburg, D., 2009. Five challenges in science education. Thornburg Center for Space Exploration. Available at<http://www.tcse-k12.org/pages/science.pdf> [Accessed 5 December 2018].

Trigwell, K., Ellis, R. and Han, F., 2012. Relations between Students' Approaches to Learning, Experienced Emotions and Outcomes of Learning. Studies in Higher Education, [e-journal] 37(7), pp. 811-824. doi:10.1080/03075079.2010.549220.

Tune, J., Sturek, M. and Basile, D., 2013. Flipped classroom model improves graduate student performance in cardiovascular, respiratory, and renal physiology. Advances in Physiology Education, [e-journal] 37(4), pp. 316-20. doi: 10.1152/advan.00091.2013.

Vázquez, A., and Manassero, M., 2007. En defensa de las actitudes y emociones en la educación científica (I): Evidencias y argumentos generales (In defense of attitudes and emotions in science education (I): General arguments and evidence). Revista Eureka sobre Ense-anza y Divulgación de las Ciencias, 4(2), pp. 247-271. Available at:< http://www.apaceureka.org/revista/Volumen4/Numero_4_2/Vazquez_Manassero_2007.pdf> [Accessed 3 August 2018]. 
Velayutham, S., and Aldridge, J., 2013. Influence of psychosocial classroom environment on students' motivation and selfregulation in science learning: A structural equation modeling approach. Research in Science Education, [e-journal] 43(2), pp. 507-527. doi10.1007/S11165-011-9273-Y.

Wang, H., and Schmidt, W., 2001. History, philosophy and sociology of science in science education: Results from the Third International Mathematics and Science Study. Science \& Education, [e-journal] 10(1-2), pp. 51-70. doi:10.1023/A:1008704531439.

Weiman, C., 2008a. Science education in the 21st century: Using the tools of science to teach science. In Forum for the Future of Higher Education, 61-64. EDUCAUSE. Available at: <http://net.educause.edu/ir/library/pdf/ff0814s.pdf> [Accessed 25 June 2018].

Wilson, S. 2013. The flipped class: A method to address the challenges of an undergraduate statistics course. Teaching and Psychology, [e-journal] 40(3), pp. 193-199. doi:10.1177/0098628313487461.

Yilmaz, R., 2017. Exploring the role of e-learning readiness on student satisfaction and motivation in flipped classroom. Computers in Human Behavior, [e-journal] 70, pp. 251 260. doi10.1016/j.chb.2016.12.085.

Yousefzadeh, M. and Salimi, A., 2015. The effect of flipped learning (revised learning) on Iranian students learning outcomes. Advance in Language and Literary Studies, [e-journal] 6(5), 209-213.

http://dx.doi.org/10.7575/aiac.alls.v.6n.5p.2 